Klinichna khirurhiia. 2018 August;85(8):72-76.

DOI: $10.26779 / 2522-1396.2018 .08 .72$

\title{
Динамика энергоструктурной активности при ингаляционной анестезии
}

\author{
О. Н. Бойцова ${ }^{1}$, Л. М. Смирнова ${ }^{2}$, Г. А. Шифрин ${ }^{1}$
}

13апорожский государственный медицинский университет,

${ }^{2}$ Национальный институт хирургии и трансплантологии имени А. А. Шалимова НАМН Украины, г. Киев

\section{Dynamics of the energy-structural activity in the inhalation anesthesia}

\author{
O. N. Boitsova ${ }^{1}$, L. M. Smirnova ${ }^{2}$, G. A. Shifrin ${ }^{1}$ \\ ${ }^{1}$ Zaporozhye State Medical University, \\ ${ }^{2}$ Shalimov National Institute of Surgery and Transplantology, Kyiv
}

\section{Реферат}

Цель. Улучшение результатов лечения больных путем придания периоперационному обеспечению ингаляционной анестезии севофлураном энергопротективной направленности.

Материалы и методы. У пациентов с острой патологией органов брюшной полости проведен аудит энергоструктурной активности во время ингаляционной анестезии севофлураном. В группе сравнения использовали общепринятый протокол, в основной - с применением органопротективных технологий. Определяли клинические индексы опасности (КИО), безопасности (КИБ), кардиальный резерв (КР), микроциркуляторно-митохондриальную недостаточность (MMH), концентрацию в крови нейроглиального белка (S100) и нейронспецифической энолазы (NSE).

Результаты. Ингаляционная анестезия севофлураном нарушает энергоструктурные взаимодействия (ЭСВ) в массе клеток тела (МКТ). Энергопротективные технологии снижают степень повреждения, о чем свидетельствовала концентрация в крови S100 и NSE.

Выводы. Применение энергопротективных технологий в соответствии с категориями энергоструктурной активности в МКТ позволяет улучшить результаты лечения пациентов с острой патологией брюшной полости и персонифицировать анестезиологическое обеспечение. Выявлена и доказана тесная корреляционная связь между ранними проявлениями структурных микроповреждений клеток головного мозга с энергоструктурными изменениями в МКТ пациентов.

ключевые слова: энергоструктурные взаимоотношения; ингаляционная анестезия; метаболизм; потребление кислорода; нейроглиальный белок; нейронспецифическая энолаза.

Abstract

Objective. To improve the treatment results for patients, using the energy-protective trend in realizing of perioperative procuring of inhalation anesthesia with sevofluran.

Materials and methods. Audit of the energy-structural activity while the inhalation anesthesia, using sevofluran, was conducted in patients, suffering acute abdominal pathology. In a comparison group of patients a conventional protocol was used, and in the main one - the organ-protective technologies. Clinical indices of danger, security, cardiac reserve, microcirculationmitochondrial insufficiency (MMH), the blood concentration of a neuroglial protein (S100) and neurospecific enolase (NSE) were detected.

Results. The inhalation anesthesia, using sevofluran, disorders the energy-structural interrelationship in the body cellular mass (BCM). The energy-protective technologies lower the affection degree, what was witnessed by the blood concentration of S100 and NSE.

Conclusion. Application of the energy-protective technologies in accordance to categories of the energy-structural activity in BCM permits to improve the results of treatment in the patients, suffering an acute abdominal pathology and to personify the anesthesiological care. Close correlational connection between early signs of structural microtraumas of cerebral cells with the energy-structural changes in the patients' BCM was revealed and proved.

Keywords: energy-structural interrelationship; inhalation anesthesia; metabolism; consumption of oxygen; neuroglial protein; neuronspecific enolase

Применение новых ингаляционных анестетиков приобретает все большую популярность у различных категорий пациентов, в том числе у пациентов с острой патологией брюшной полости. Во время неотложных хирургических вмешательств ингаляционная анестезия имеет ряд преимуществ: быстрая индукция, хорошая управляемость и высокая скорость изменения глубины наркоза, низкая токсичность и короткий период пробуждения после операции [1 - 4]. Однако использование ингаляцион- ных анестетиков, в частности севофлурана, не исключает периоперационных нарушений ЭСВ в МКТ, проявляющихся изменениями высших корковых функций $[5,6]$.

ЭСВ в МКТ и нарушение жизнедеятельности специализированных клеток головного мозга при ингаляционной анестезии до настоящего времени остаются неизученными.

Цель исследования: улучшение результатов лечения больных путем придания периоперационному обеспе- 
чению ингаляционной анестезии севофлураном энергопротективной направленности.

\section{Материалы и методы исследования}

Изучены результаты периоперационного аудита ЭСВ, их свойств, резервов и эффективности ауторегуляции у 112 больных с острой патологией брюшной полости [7]. В исследование включены больные в возрасте от 18 до 86 лет, из них 79 (70,5\%) женщин и 33 (29,5\%) мужчины. Операционно-анестезиологический риск определяли по уровню ЭСВ [7] и по шкале физического статуса Американского общества анестезиологов (ASA). Оперативные вмешательства выполняли в условиях общей анестезии на основе севофлурана. Продолжительность операций варьировала от 35 до 130 мин.

В периоперационном периоде исследовали глубокую картину кислородного режима, показатели гемодинамики и микроциркуляции, проводили непрямое определение основного обмена. Неинвазивный мониторинг осуществляли с помощью интегрированного монитора "Leon". Газовый состав крови определяли с помощью аппарата "ABL 800 FLEX" (Radiometr, Дания). У всех пациентов, независимо от уровня ЭСВ в МКТ, методом иммуноферментного анализа определяли маркеры ранних признаков повреждения нейронов - S100 и NSE - с помощью диагностических наборов CanAg S100 EIA и CanAg NSE EIA (Fujirebio diagnostics AB, Швеция).

Об энергоструктурной стабильности организма судили по показателю потребности в потреблении кислорода, который зависит прежде всего от возможности систем жизнеобеспечения удовлетворить эту потребность [8]. Уровень ЭСВ в МКТ и их свойства (адаптивность, стабильность, адекватность), резервы ауторегуляции (миокардиальный, кислороднотранспортный, микроциркуляторно-митохондриальный) и эффективность ауторегуляции (гемодинамической, энергоосмолярной) определяли на конкретных в соответствии с протоколом исследования этапах периоперационного периода [5, 7]. Изменения уровня ЭСВ в МКТ оценивали путем сравнения интенсивности текущей энергопродукции и транспорта кислорода с их должными значениями [7, 8]. КИБ рассчитывали как разность величин надежности и потребности в ЭСВ, выраженную в процентах [8].

Для характеристики количественных данных, полученных после статистической обработки материалов исследования, распределение которых не отвечало референтным значениям, использовали первый и третий квартили (25 и 75\%) «Statistica® for Windows 6.0». В таблице указывали медиану - целые значения числа в процентах.

В соответствии с исходным уровнем были выделены три категории ЭСВ в МКТ: дисфункция - констатирована у 35 (31\%) пациентов (класс ASA I-II E, MPI 12-15 баллов), повреждение - у 56 (50\%) пациентов (класс ASA IIIII E, MPI 16-21 баллов), недостаточность - у 21 (19\%) пациента (класс ASA III E, MPI 22-25 баллов).

По каждой категории пациентов разделили на две группы: основную и сравнения. Группы репрезентативны по полу, возрасту, характеру хирургической патологии, степени анестезиологического риска.
Пациентам всех групп применяли ингаляционную анестезию на основе севофлурана. Отличительной особенностью анестезиологического обеспечения в основных группах было дополнительное использование местного анестетика до начала операции и технологий восстановления ЭСВ в МКТ [8]. Лидокаин применяли с целью профилактики интубационного стресса и минимизации доз миорелаксантов, предупреждения нежелательного ослабления наркозного потенциала и связанного с этим пробуждения пациента во время операции.

При дисфункции ЭСВ в МКТ проводили искусственную энергобиотию: поддерживали целевые цифры артериального давления (АД), при этом среднее артериальное давление (АД ${ }_{\text {ср }}$ ) колебалось в пределах от 11,3 до 12,0 кПа (от 85 до 90 мм рт. ст.); энергопротективный уровень частоты сердечных сокращений (ЧСС) соответствовал 54 - 86 в 1 мин и достигался применением кордарона либо М-холинолитиков; коэффициент соотношения диастолического и систолического АД соответствовал референтному уровню $0,599-0,636$, при необходимости его регулировали применением ß-блокаторов или ингибиторов АПФ. Эффективность искусственной вентиляции легких (ИВЛ) оценивали на основании результатов исследования кислотно-основного состояния. Альвеолярная вентиляция колебалась в пределах 4,8 - 5,2 л/мин с процентным содержанием кислорода во вдыхаемой смеси $\left(\mathrm{FiO}_{2}\right)$, равным 0,3 - 0,4, и концентрацией углекислого газа $\left(\mathrm{CO}_{2}\right)$ в альвеолярном газе от 6,3 до 6,5\%. Выбранные и контролируемые параметры ИВЛ позволяли формировать и поддерживать у пациентов состояние нормокарбонатемии $\left(\mathrm{HCO}_{3}\right.$ от 23,5 до 24,5 ммоль/л) и венозной нормоксии $\left(\mathrm{p}_{\mathrm{v}} \mathrm{O}_{2}\right)$ на уровне 5,0 - 5,5 кПа $(37,5-41,5 \mathrm{Mм}$ рт ст.). Водный баланс поддерживали полиионными растворами из расчета 40 мл на 20 кг массы тела (МТ) плюс 10 мл/кг оставшейся части МТ под контролем диуреза. При необходимости проводили стимуляцию диуреза салуретиком. Также при необходимости устраняли дефицит электролитов.

При повреждении ЭСВ в МКТ применяли метод энергоресуститации: инфузионно-трансфузионную терапию, предназначенную для создания напряженного объема крови, проводили под контролем центрального венозного давления (ЦВД) с соблюдением правила «5 - 2»; насосную функцию сердца стабилизировали добутамином в дозе не менее 6 мкг/(кг×мин), в случае гипертензивного ответа на инотропную дозу, не снижая последнюю, систолическое АД поддерживали на уровне 16,7 - 18,0 кПа (125 - 135 мм рт. ст.) введением урапедила. Стабильность деоксигенации гемоглобина не нарушается при малообъемной нормокарбонатемической ИВЛ с частотой дыхания (ЧД) от 7 до 12 в 1 мин и альвеолярной вентиляцией, составляющей в среднем 4,8 - 5,2 л/мин, с FiO ${ }_{2}$ не более 0,4. Поддерживали гематокрит (Ht) на уровне $30-40 \%$ и АДср - $(12,0 \pm 0,7)$ кПа $(90,0 \pm 5,0)$ мм рт. ст. Блокаду микроциркуляции устраняли под контролем антитромбина III. При тахикардии ЧСС регулировали кордароном, при брадикардии - М-холинолитиками до референтных значений нормосистолии $54-86$ в 1 мин. Устраняли дефицит электролитов, общего белка и гемоглобина. 
При недостаточности ЭСВ в МКТ проводили статускоррекцию, которая отличается от энергоресусцитации тем, что технологию энергоресуститации дополняли эфферентными и афферентными методиками деблокирования микроциркуляторного русла, энтеральной оксигенацией, управляемой нормотермией.

\section{Результаты}

Параметры категорий ЭСВ и концентрации нейроспецифических белков представлены в таблице.

При дисфункции ЭСВ в МКТ у пациентов основной группы наблюдали отклонение ЭСВ до уровня, который отвечает значениям КИО - 11\%. У пациентов группы сравнения отклонения ЭСВ от уровня энергоструктурной надежности не отмечали, а КИБ составил 3\%.

При энергоструктурном повреждении предоперационная подготовка у пациентов основной группы проведена в соответствии с концептуальной трансфузионной терапией и управляемой изоосмолярностью. Применение новых технологий способствовало ликвидации исходных энергоструктурных нарушений уже при поступлении пациентов в операционную, о чем свидетельствует КИБ, медиана которого составила 7\%. В группе сравнения при стандартной методике предоперационной подготовки фиксировали КИО на уровне 9\% (р < 0,05).

При недостаточности ЭСВ у пациентов основной группы и группы сравнения КИО составлял 23 и 24\% соответственно. Применение в основной группе инновационной предоперационной подготовки способствовало стабилизации КР на уровне 56\% еще до начала операции. Стандартные методики подготовки не столь эффективны и КР был на 43\% ниже, чем в основной группе, и составил 33\% (p<0,05).

При дисфункции ЭСВ в МКТ у пациентов обеих групп до операции уровень нейроспецифических белков соответствовал общепринятым нормам. При повреждении ЭСВ в МКТ исходные значения маркеров энергоструктурных повреждений нейронов и нервных проводников превышали референтные уровни (S100 составил 162 нг/л - в основной и $133 \mathrm{Hг} / л$ - в группе сравнения, NSE 21 и 9 мкг/л соответственно). При недостаточности ЭСВ в МКТ уровень нейроспецифических белков у больных существенно отличался от референтного и имел более выраженный характер: уровень S100 в основной группе составил 281 нг/л ( $<0,05)$, уровень NSE в группе сравнения - 31 мкг/л $(\mathrm{p}<0,05)$.

В основной группе и группе сравнения опасность развития энергоструктурных нарушений под действием операционной травмы и анестезии возрастала, тем не менее отклонение показателя до 15\% не является критичным. Невзирая на то что КР был выше в группе сравнения, адаптационные возможности организма оказались на 10\% выше в основной группе, что подтверждается уровнем нейроспецифических пептидов. Показатели, характеризующие кислородно-транспортную и микроциркуляторно-митохондриальную системы, соответствовали уровню недостаточности в обеих группах и колебались в незначительных пределах.

При повреждении ЭСВ КИО в конце операции в основной группе составлял 13\%, в группе сравнения - 22\% (p <

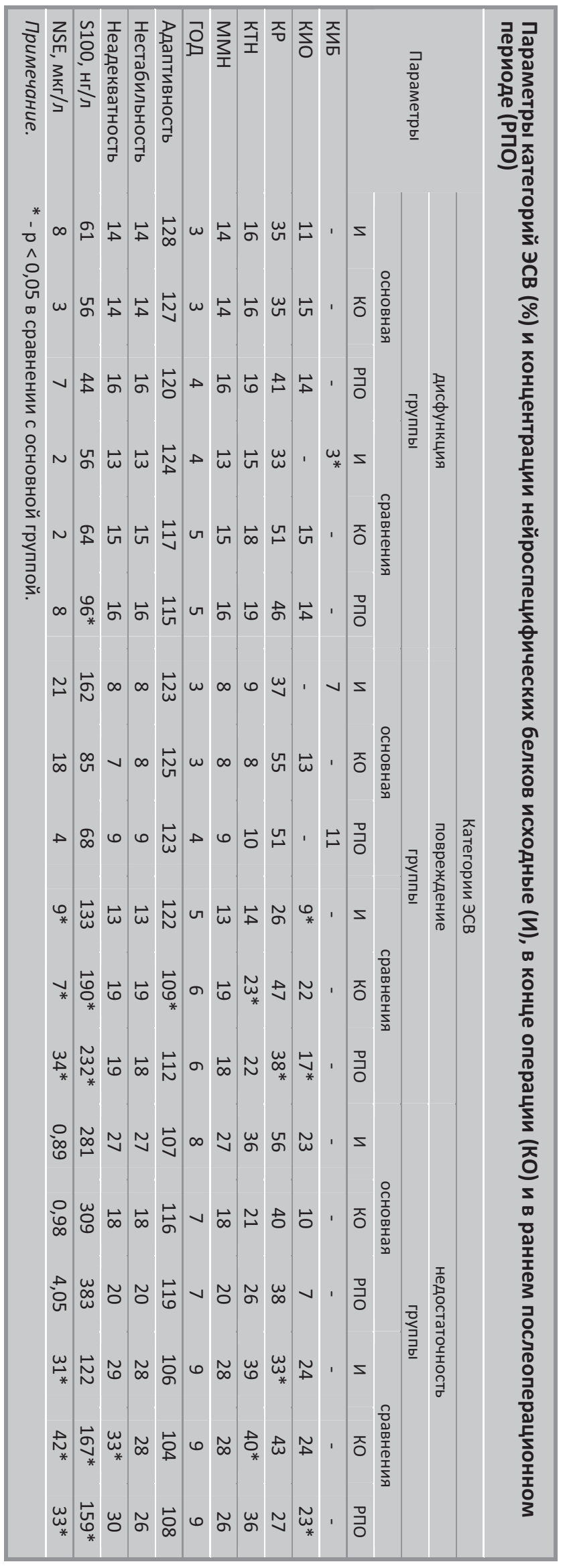


0,05). Наиболее высокие значения КР в конце операции регистрировали в основной группе, что можно объяснить способностью метода энергоресуститации обеспечивать фармакологическую нормосистолию.

Эффективность ауторегуляции внутриклеточных процессов отражает гипоосмолярная дестабилизация (ГОД), которая в основной группе была уменышена почти в 2 раза по отношению к группе сравнения за счет управляемой изоосмии. Адаптивность при стандартном обеспечении была меньше на 16\%, чем в основной группе, что существенно усугубляло показатели нестабильности и неадекватности энергоструктурных взаимоотношений. Применение метода энергоресуститации способствовало в конце операции снижению концентрации S100 на 47,5\% и концентрации NSE на 14,2\% по сравнению с исходными данными. В группе сравнения показатель S100 увеличился на 31\%, a NSE не претерпел существенных изменений.

Окончание оперативного лечения при недостаточности ЭСВ характеризовалось снижением опасности гипоксическо-ишемических повреждений: в основной группе - на 10\%, в группе сравнения - на 5\%. При стандартном анестезиологическом обеспечении периоперационная опасность оказалась выше на 4 - 5\%. ГОД наблюдали в обеих группах пациентов, однако превышение допустимого уровня составляло не более $3 \%$ надежной величины осмотического давления. В основной группе ГОД на всех этапах исследования была на 1 - 2\% меныше, чем в группе сравнения. Отличительной чертой свойств ЭСВ в обеих группах являлась абсолютная их нестабильность, преобладающая в группе сравнения, где показатель нестабильности оказался выше на 14 - 18\%. Концентрация S100 в группе сравнения была в 1,85 раза ниже, нежели в основной.

Ингаляционная анестезия, дополненная методом регулируемой искусственной энергобиотии, у пациентов с дисфункцией ЭСВ способствовала стабилизации КИО на уровне $15 \%$, что и послужило ограничивающим моментом дополнительного повреждения ЭСВ в МКТ в послеоперационном периоде. Стандартная методика применения севофлурана оказалась неспособной стабилизировать состояние ЭСВ на безопасном для пациента уровне, что подтверждал КИО, возросший до 23\%. Стабилизации осмолярности плазмы (изоосмолярности) как в основной, так и в группе сравнения достигнуто не было, при этом нарушения носили гипоосмолярный характер. В группе сравнения ГОД превысила допустимый уровень на 2\%, что чревато деформацией МКТ и дополнительными нарушениями их энергосопряженности. Уровень S100 в основной группе оказался ниже, чем в группе сравнения на $54,1 \%$ ( $<0,05)$. Такая же тенденция отмечена в отношении уровня NSE - снижение составило 12,5\% ( $<$ 0,05). Таким образом, в отличие от пациентов основной группы, стандартное периоперационное обеспечение в группе сравнения не гарантировало исключения серьезных внутриклеточных нарушений.

При повреждении ЭСВ завершение энергоресуститации обеспечивало в раннем послеоперационном периоде надежную безопасность оперированных пациентов - КИБ составил 11\%. В группе сравнения фиксировали КИО на уровне 17\% ( $<$ 0,05). Эффективность ауторегу- ляции внутриклеточных процессов отражают изучаемые показатели ЭСВ. В послеоперационном периоде отмечали меньшую степень повреждения у пациентов основной группы, что и подтверждала концентрация в крови нейроспецифических пептидов.

\section{Обсуждение}

Сопоставление результатов клинического исследования показало, что стандартное периоперационное обеспечение затрудняет энергоструктурную адаптивность, которая на всех этапах исследования, кроме исходного, оказалась ниже, чем в основной группе. Показатель нестабильности ЭСВ на всех этапах исследования был вдвое выше в группе сравнения. В раннем послеоперационном периоде в основной группе выявлено увеличение концентрации S100 в 3,4 раза, в то время как концентрация NSE в 7,5 раза была ниже по сравнению с группой, где применяли стандартное анестезиологическое обеспечение.

Периоперационные качественные и количественные изменения, сопряженные с непосредственным вовлечением нервной ткани в патологический процесс, дают ценную информацию остепени выраженности повреждений нейронов и нарушениях общей целостности гематоэнцефалического барьера, постишемического повреждения мозга. Таким образом, периоперационное применение метода энергоресуститации позволяет уменьшить выраженность внутриклеточных повреждений, включая элементы головного мозга.

Включение в анестезиологическое пособие при недостаточности ЭСВ элементов статус-коррекции позволило поддерживать периоперационные ЭСВ на уровне ниже исходных значений выключения части клеточных элементов из надежной энергопродукции. Стандартное анестезиологическое обеспечение оказалось неспособным улучшить периоперационное состояние ЭСВ, так как интенсивность энергопродукции была на 25\% ниже уровня надежности. В конце исследования концентрация NSE в группе сравнения оставалась высокой (медиана соответствовала 33 мкг/л), в то время как в основной группе ее уровень не отличался от референтного. NSE - единственный известный в настоящее время общий маркер всех дифференцированных нейронов, дающий ценную информацию о степени выраженности их повреждений. Следовательно, персонифицированные технологии гарантируют высокую степень периоперационной защиты пациентов от повреждающего воздействия ишемии и гипоксии.

\section{Выводы}

1. Определение категории ЭСВ в МКТ позволяет улучшить результаты лечения пациентов с острой патологией органов брюшной полости за счет применения энергопротективной технологии, что персонифицирует периоперационное анестезиологическое обеспечение.

2. Выявлена и доказана тесная корреляционная связь между ранними проявлениями структурных микроповреждений клеток головного мозга и энергоструктурными изменениями в МКТ пациентов.

3. Стандартная ингаляционная анестезия, дополненная энергопротективными технологиями, способству- 
ет уменьшению выраженности не только повреждения энергоструктурного статуса, но и связанного с ним повреждения нейронов и нейроглии, что придает анестезиологическому обеспечению энергопротективную направленность,

4. Применение энергопротективных технологий существенно повышает периоперационную энергопротективную способность ингаляционной анестезии.

\section{References}

1. Lihvancev VV, Grebenchikov OA, Borisov KJu, Shajbakova VL, Shaposhnikov AA, Cherpakov RA, et al. Mehanizmy farmakologicheskogo prekondicionirovanija mozga i sravnitel'naja jeffektivnost' preparatov - ingibitorov glikogen-sintetazy-kinazy -3 beta prjamogo i neprjamogo dejstvija (jeksperimental'noe issledovanie). Obshhaja reanimatologija. 2012;8(6): 37-42. [In Russian].

2. Wang H, Shi H, Yu Q, Chen J, Zhang F, Gao Y. Sevoflurane preconditioning confers neuroprotection via anti-apoptosis effects. Acta Neurochir Suppl. 2016;121:55-61. DOI: 10.1007/978-3-319-18497-5_10.

3. Miller RD, editor. Miller's Anesthesia. 8th edition. Philadelphia, PĀ: Elsevier/Saunders; 2014. 3576 p.

4. Brioni JD, Varughese S, Ahmed R, Bein B. A clinical review of inhalation anesthesia with sevoflurane: from early research to emerging topics. J Anesth. 2017 Oct;31(5):764-78. DOI: 10.1007/s00540-017-2375-6.

5. Usenko LV, Krishtafor AA, Polinchuk IS, Tjutjunnik AG, Usenko AA, Petrashenok EV. Posleoperacionnye kognitivnye rasstrojstva kak oslozhnenija obshhej anestezii. Znachenie rannej farmakologicheskoj nejroprotekcii. Medicina neotlozhnyh sostojanij. 2015 Ijun’ 4;2(65):2431. [In Russian].

6. Fesenko UA, Khyzhniak KA. Problema kohnityvnykh dysfunktsii v anesteziolohii. Bil, zneboliuvannia i intensyvna terapiia. 2012;2(59):47-59. [In Ukrainian].

7. Shifrin GA. Personifikacija perioperacionnoj bezopasnosti: posobie. Zaporozh'e: Dikoe Pole; 2016. 88 p. [In Russian].

8. Kolesnik JuM, Tumanskij VA, Shifrin GA. Osnovy vrachebnoj kompetentnosti. Zaporozh'e: Dikoe Pole; 2013. 376 p. [In Russian]. 